Popular Summary

"Ground Clutter as a Monitor of Radar Stability at Kwajalein, RMI"

David S. Silberstein, David B. Wolff, David A. Marks, David Atlas and Jason L. Pippitt

SSAI/NASA/GSFC/613.1

Submitted to the Journal of Atmospheric and Oceanic Technology September, 2007

A vital task of all those working on the Tropical Rainfall Measuring Mission (TRMM), or using the resulting data, is the validation of the accuracy of the rainfall measurements by the TRMM satellite. This is a primary responsibility of the Ground Validation (GV) team at NASA GSFC. One of the GV team's goals has been the review and correction of the observations made by the weather radar located on Kwajalein Atoll, the only GV site in the tropical Pacific ocean. The quality of this radar data has been adversely affected by many factors: deliberate system modifications, equipment failures in a harsh tropical environment, and other unknown causes. Such impacts on radar measurements produce subsequent errors in rainfall estimates, the quality of which is critical to the success of the GV mission. Thus, it was necessary to find a means of correcting such errors on a routine basis.

Radar returns from surface structures such as buildings and towers have been used since World War II as a qualitative measure of radar performance. The GV team developed the Relative Calibration Adjustment (RCA) method, which uses a statistical technique to analyze ground targets and assess the current state of the radar calibration. This is done in an automated fashion and on a daily basis. Any changes in radar performance are well detected by the analysis. The method has revealed previously undetected changes in sensitivity due to alteration of the radar's physical characteristics. Further, the RCA has made possible the improvement of radar rain rate estimates, insuring the integrity of TRMM observations, which have become the basis for the near global climatology of the water budget, as well as other purposes such as the monitoring of hurricane intensity. Such improvement to a previously problematic data set has protected the investment of federal resources toward maintaining the Kwajalein site of well over one million dollars and numerous man-years of effort over the life of the program (1999-present). The method has also shown promise for any ground-based radar that has ground targets in proximity of the radar. 


\title{
Ground Clutter as a Monitor of Radar Stability at Kwajalein, RMI
}

\author{
David S. Silberstein $^{1,2}$, David B. Wolff ${ }^{1.2}$, David A. Marks ${ }^{1,2}$, \\ David Atlas ${ }^{1}$, and Jason L. Pippitt ${ }^{1,2}$
}

${ }^{I}$ NASA Goddard Space Flight Center, Laboratory for Atmospheres, Greenbelt, Maryland

${ }^{2}$ Science Systems and Applications, Inc., Lanham, Maryland

Corresponding Author's Address:

David S. Silberstein

NASA/GSFC, Code 613, Greenbelt, MD 20771.

David.S.Silberstein@nasa.gov 


\begin{abstract}
There are many applications in which the absolute and day-to-day calibration of radar sensitivity is necessary. This is particularly so in the case of quantitative radar measurements of precipitation. While absolute calibrations can be done periodically using solar radiation, variations that occur between such absolute checks are required to maintain the accuracy of the data. The authors have developed a method for this purpose using the radar on Kwajalein Atoll, which has been used to provide a baseline calibration for control of measurements of rainfall made by the Tropical Rainfall Measuring Mission
\end{abstract} (TRMM). The method uses echoes from a multiplicity of ground targets. The average clutter echoes at the lowest elevation scan have been found to be remarkably stable from hour to hour, day to day, and month to month within better than $\pm 1 \mathrm{~dB}$. They vary significantly only after either deliberate system modifications, equipment failure or unknown causes. A cumulative probability distribution of echo reflectivities ( $Z e$ in $\mathrm{dBZ}$ ) is obtained on a daily basis. This CDF includes both the precipitation and clutter echoes. Because the precipitation echoes at Kwajalein rarely exceed $45 \mathrm{dBZ}$, selecting an upper percentile of the CDF associated with intense clutter reflectivities permits monitoring of radar stability. The reflectivity level at which the CDF attains $95 \%$ is our reference. Daily measurements of the CDFs have been made since August 1999 and have been used to correct the $71 / 2$ years of measurements and thus enhance the integrity of the global 
record of precipitation observed by TRMM. The method also has potential applicability to other ground radar sites. 


\section{Introduction}

A vital task of all those working on the Tropical Rainfall Measuring Mission (TRMM) or using the resulting data is the validation of the accuracy of the rainfall measurements by the Precipitation Radar (PR). This is a primary responsibility of the Ground Validation (GV) team. One of our goals has been the review and correction of the observations made by the KPOL radar on Kwajalein Atoll. Radar specifications are outlined in Table 1. Changes in radar sensitivity can be caused by either deliberate system modifications, equipment failures or unknown causes.

The best checks of absolute system sensitivity have been made from time to time using observations of solar radiation. However, sensitivity changes have occurred on other occasions that have produced errors in the precipitation reflectivity and thus in the rainfall. It was therefore necessary to find a means of correcting such errors on a routine basis, even daily. We then chose to use echoes from fixed ground structures or ground clutter, as had been done previously in a more limited manner by Rinehart (1978). Indeed, echoes from well defined structures have been used since WW II as a qualitative measure of radar performance. 
The present approach involves use of the statistics of the clutter reflectivities at the lowest level of scan on rain-free days and similar statistics of the combination of clutter and precipitation reflectivities when raining. A change in system sensitivity alters the features of the probability distributions in a well-defined manner. The goals of this work are: 1) to develop the method; 2) to demonstrate the manner in which it determines changes in system sensitivity whenever they occur; 3) to provide a long term record of the system sensitivity changes; and 4) to indicate how we plan to correct the KPOL observations and thereby enhance the integrity of the $71 / 2$ year global archive of rainfall measured by TRMM.

\section{Background}

A comprehensive review of the nature of ground clutter in a variety of environments is available in Skolnik (2001, Chapter 7). Further details may be found in the papers by Billingsley and Larrabee (1991) and Billingsley (1993) as well as others in the Skolnik review. For present purposes it suffices to know that most of the significant clutter echoes at low angles come from spatially localized or discrete vertical features associated with high regions of the visible landscape (e.g. trees, buildings, or multiple 
towers). An aerial view of Kwajalein Island is shown in Figure 1. Except for the case of echoes from wind-driven trees, the echoes do not fluctuate as do those from precipitation. The reflections from clutter do not behave as those from point targets with inverse fourth power range dependence. Rather, they depend upon the range dependence of the target characteristics. Each echo is the cumulative sum of the reflections from structures within a half pulse length. Those from structures with flat surfaces normal to the radar beam are the strongest. The reader is referred to Skolnik (2001, Table 7.1 and Figs. 7.4 and 7.5) for details on the typical strength of clutter echoes from various types of terrain as a function of wavelength.

A significant study indicative of the utility of ground clutter in the present context is the work of Fabry et al. (1997) and Fabry (2004) in which they have used the phase shift of the echoes from various ground targets to measure the path average refractive index and thus the relative humidity between target and radar. This requires that the selected targets produce strong and stable echoes. We shall see that the latter features characterize the nature of the clutter targets in this work.

In what follows the Sigmet ${ }^{\circledR}$ Corporation RVP8 signal processor averages the echoes and produces a digital measure of the reflectivity factor $10 \log Z$ in $d B Z$. The 
processor does the same for ground clutter with or without the presence of precipitation.

Using the radar equation

$$
\operatorname{Pr}=\mathbf{C Z} / \mathrm{R}^{2}
$$

where $\operatorname{Pr}$ is the echo power, $R$ is range, $Z$ is either the sum of rain reflectivity $\left(Z_{r}\right)$ and clutter reflectivity $\left(\mathrm{Z}_{c}\right)$ or clutter alone, and $\mathrm{C}$ includes all the "constant parameters" of the radar such as transmitted power, beam width and pulse width. Taking common logarithms,

$$
10 \log Z=10 \log P r+20 \log R-10 \log C \quad(d B Z)
$$

In accord with common practice in radar meteorology, we simply refer to $10 \mathrm{Log} Z$ as $\mathrm{Z}$ in $\mathrm{dBZ}$. Since range is known for all targets, $10 \mathrm{LogC}$ represents the radar sensitivity in $\mathrm{dB}$ so that any change in system sensitivity will shift the probability density function (PDF) of the echoes by $\Delta(10 \log C) \mathrm{dB}$. Although the clutter echo does not vary as the inverse square of range, as long as its PDF remains constant or is dominated by targets in a small range interval (as will be shown below), the clutter will remain a reliable reference. Table 2 contains the distribution of clutter as a function of range. Nearly $77 \%$ of points are within $5 \mathrm{~km}$ of the radar, almost $90 \%$ within $10 \mathrm{~km}$. 
Because the method requires constancy of the PDF of the clutter reflectivity we have examined the possible affects of anomalous propagation over all relevant intervals from hours to months and found no significant variations. This is probably due to the oceanic tropical environment of Kwajalein.

\section{The RCA Method Defined}

In order to arrive at the most reliable estimates of reflectivity, the GV team must address numerous sources of non-precipitation related reflectivity returns. One of these sources is ground clutter in the vicinity of the radar that can be generated by buildings and other physical structures. A clutter map was developed by constructing a mask where there was a relatively high probability of echo detection in the absence of precipitation. These regions were identified according to range and azimuth from the radar and a database was constructed containing 1323 range-azimuth pairs. This database was used to establish a clutter map, displayed in Fig. 2, that is used to eliminate echoes for purposes of quality control. The outline of the clutter does not correspond to the Kwajalein island alone but to the group of islands comprising the entire atoll. 
The 1323 range-azimuth pairs are from observations at 1 degree of azimuth and 1 $\mathrm{km}$ in range. For each degree of azimuth, observed reflectivity, hereafter referred to as reflectivity, is recorded at individual gates with $264 \mathrm{~m}$ spacing (200 $\mathrm{m}$ gate spacing after 1 March 2005). The reflectivity at each gate was extracted from the TRMM standard product 1C-51 data. This product is described more fully in Wolff et al. (2005). Because there are roughly four gates $\mathrm{km}^{-1}$, this extraction provides approximately 5000 reflectivity measurements (more than 6500 after 1 March 2005) within the clutter region for a full sweep of the radar. During the course of a day, with volume scans approximately every 6 minutes, there can be up to 240 sweeps resulting in daily clutter data sets containing over $10^{6}$ samples.

The PDFs and CDFs for consecutive days from August 2003 are depicted in Fig. 3. The shift in the mode of the PDF between 18 August (solid lines) and 19 August (dashed lines) is the same as that throughout the entire CDF. (Each PDF is based on an entire day of data.) It is worth noting that the meteorology on these two dates is quite similar with only widely scattered rainfall on both dates; however, the CDFs for these two consecutive dates differ considerably at higher reflectivities, indicating a change in Zc. Independent engineering logs provided by 3D Research Corporation (3DRC) reveal 
that this particular change is directly tied to the replacement of a directional coupler on 19 August.

In the second half of 2001 , it was generally accepted that the KPOL radar was operating in a relatively stable mode as determined by engineering logs. The PDFs and CDFs for 5 October and 20 October are displayed in Fig. 4. It is known from a visual inspection of radar images that very different meteorological conditions existed on these two days. On 5 October (solid lines), numerous organized rain bands traversed the site, while on 20 October (dashed lines), precipitation was generally light and widely scattered. Because reflectivity associated with precipitation rarely exceeds $45 \mathrm{dBZ}$ at Kwajalein, the combined $\mathrm{CDF}$ of $\mathrm{Z}_{\mathrm{c}}$ and $\mathrm{Z}_{\mathrm{r}}$ will reach $100 \%$ close to that level under ordinary circumstances, i.e. the best absolute value of $\mathrm{C}$. However when $\mathrm{C}$ changes with a sensitivity change, the new combined CDF will attain $100 \%$ at either a smaller or larger reflectivity value depending upon whether $10 \operatorname{LogC}$ increases or decreases, respectively. Empirical tests have shown that the $95^{\text {th }}$ percentile of the CDF is a very reliable indicator of such changes and provides robust sampling ( 50000 values per day). This is the level to which we refer through the remainder of this paper. An evaluation of the $95^{\text {th }}$ percentile of daily CDFs over the $71 / 2$ years of data processed is displayed in Fig. 5 . It is evident that there are periods of relative calibration stability as well as periods where the 
calibration undergoes significant changes. Most of these readily apparent calibration changes have been directly tied to significant engineering events such as the failure or replacement of major radar components. These relationships between time record behavior and engineering indicate that changes in radar calibration can be clearly detected by the RCA method, and thus prevent their misinterpretation as meteorological phenomena.

In order to provide daily data adjustments, knowing the $95^{\text {th }}$ percentile time record is an essential requirement. However, it is also necessary to establish a baseline and that can only be accomplished if there is a high degree of confidence in the calibration at a particular time. Fortunately, as a result of the intensive KWAJEX field campaign conducted in 1999 (Yuter et al. 2005) and subsequent collaboration among several institutions (NASA, Colorado State Univ., Univ. of Washington), a consensus was reached among researchers that the radar was running about $6 \mathrm{~dB}$ too low, based on comparisons with the TRMM precipitation radar (PR), and other methods, during the month of August 1999. The RCA baseline was thus established by adding $6 \mathrm{~dB}$ to the $95^{\text {th }}$ percentile value of 1 August 1999, making that summation the reading to which all subsequent days would be compared. The original value on 1 August is $44 \mathrm{dBZ}$, therefore the baseline value was set to $50 \mathrm{dBZ}$. To calculate the RCA, the daily $95^{\text {th }}$ 
percentile value is subtracted from the baseline value. The result of this calculation for the period of August 1999 through 2006 is plotted in Fig. 6. It is clear that there are periods where the radar sensitivity runs low and positive adjustments are required; the converse in true when the sensitivity is high. Even though there are relatively stable periods, it is worth noting that almost every day may require some adjustment, as the RCA is rarely equal to zero. Given that the majority of the daily data will undergo at least some revision with major adjustments in certain cases, it is vital to assess the extent to which engineering issues affect the continuity and stability of KPOL data and demonstrate how the RCA can produce accurate precipitation reflectivities.

To initially check the validity of the RCA results, a comparison was made with the KPOL calibration corrections presented in Houze et al. (2004) (their Table 2), which relied on the documented stability of the TRMM PR (Kozu et al. 2001). For several periods in the above referenced table, the RCA results compared quite favorably. As shown in Fig. 7, both RCA and UW adjustments were initially $+6 \mathrm{~dB}$ in early August 1999. Both RCA and UW offsets track each other within 1-2 dB. The UW offsets remain constant over long time periods (e.g. December 2000 to August 2001) until the analysis of the next rainy PR overpass in combination with engineering logs. Because only a small number of TRMM overpasses with substantial rain occur in any month, the 
nearly $95 \%$ of the clutter field. This may be due to the fact that there are multiple targets in the pulse volume or that specific targets may consist of more complicated geometries not properly characterized by a point target formulation. Another way to examine the potential effect of range is to examine the actual day-to-day changes in the RCA ( $\triangle R C A)$ for different ranges of data accepted. Table 4 displays the $\triangle \mathrm{RCA}$ values for ten days in July 2007 for data within 1,5 and $10 \mathrm{~km}$. It can be seen that the day-to-day differences across the various ranges differ only slightly, an indication that range effects are minimal. Given this outcome, and in the interest of obtaining as many samples as possible, the entire clutter field is considered in the RCA analysis.

\section{Calibration Case Study}

The PDFs and CDFs for two days in May 2004, another period of unstable radar calibration, are displayed in Fig. 9. Although the meteorological conditions on these two days are similar with widely scattered showers, the PDFs reveal that there is a substantial jump in the calibration from 7 May (solid lines) to 8 May (dashed lines). The increase in $\mathrm{Zc}$ of approximately $8 \mathrm{~dB}$ at the $95^{\text {th }}$ percentile is one of the largest changes observed on consecutive days. As was the case with the August 2003 example described in Section 3, the calibration change during May 2004 can be directly tied to a documented engineering 
event: the changing of the directional coupler loss from $50.47 \mathrm{dBZ}$ to $48.1 \mathrm{dBZ}$ on 7 May.

The impact of such a sudden and extreme change in calibration can also be seen in the actual radar imagery. Two radar images, taken almost exactly 24 hours apart, are presented in Figs. 10a, b. It is evident from a comparison of these two figures that a significant calibration event had occurred. Not only are the 8 May reflectivities higher in the region of the clutter field but across the entire radar domain as well, an indication that what was happening in the clutter region was also affecting the entire reflectivity field.

\section{Controlled KPOL Calibration Offset Test}

In February 2007, in cooperation with the 3DRC radar operations staff, a test was performed to examine whether the RCA could accurately depict a prescribed calibration offset at KPOL. The test was structured so that within a span of three days, during a meteorologically quiescent period with no other engineering tasks scheduled, the operator first decreased both the horizontal and vertical calibration offset factors by $2 \mathrm{~dB}$ from their nominal values and then increased calibration offset factors by $2 \mathrm{~dB}$ above their nominal values. The PDFs for three days are presented in Fig. 11. The results clearly 
show that for reflectivities typical of clutter there is an approximate shift about the 8 February PDF of $\pm 2 \mathrm{~dB}$. The direct impact of this shift in the PDFs can be seen more clearly in the plot of the daily RCA values over this period, depicted in Fig. 12. The RCA value on 10 February is approximately $2 \mathrm{~dB}$ greater than the 8 February value as one would expect for a decrease in calibration offset (a leftward shift of the PDF), while the 11 February RCA value is approximately $2 \mathrm{~dB}$ less than the 8 February value as one would expect for an increase in calibration offset (a rightward shift of the PDF). This result seems to indicate that in the absence of major engineering issues, such as an inaccurately pointed radar beam, the RCA has the capability to track calibration related drift that may occur for any number of reasons directly or indirectly impacting the power output of the radar.

\section{Elevation Angle Inconsistencies Detected By The RCA}

A series of events occurred in 2006 that further highlighted the capability of the RCA to detect not only changes in calibration, but also changes in the actual pointing angle of the KPOL radar. Two prominent spikes in the RCA time record can be seen in Fig. 6 during early 2006. This portion of the time record is expanded in Fig. 13 to display the period from March through May of 2006. In the first period of interest 
(marked "a"), the RCA jumps over $10 \mathrm{~dB}$ to a value approaching $12 \mathrm{dBZ}$ before settling back to a value near $0 \mathrm{dBZ}$, all of this happening in a span of five days. Clearly, a major engineering event occurred during this period and a careful examination of the radar logs provided the explanation. Testing of a new solar calibration software utility (SIGMET ${ }^{\circledR}$ SUNCAL) indicated that the antenna's offset was not on track. On 10 April, the antenna offset was adjusted from -18 to -17.2 degrees, and then reset to -18 degrees on 15 April . As a result of this particular incident, the authors realized that they were not only dealing with changes in calibration, but also with a separate issue related to the changes in the elevation angle of the radar beam. The sensitivity is such that for every 0.1 degree increase in beam elevation angle, the RCA increases approximately $1 \mathrm{~dB}$. In addition to this event, another would occur at the end of May that would prove that changes in the elevation angle of the radar antenna strongly impact RCA calculations. During May 2006, a calibration team arrived at Kwajalein to perform their yearly investigation (Smith et al. 2007). While there, they ran the SIGMET $®$ solar calibration utility and as a result of their findings the antenna offset was adjusted from -18 to -17.25 degrees. The impact of this change is clearly evident in Fig. 13 (marked "b"), concurrent with another substantial increase in the RCA. This confirms that elevation angle modification can greatly alter the RCA. Based upon preliminary analysis, the authors believe that during these identified periods as well as others impacted by angular inconsistency, it is 
inappropriate to directly apply the RCA to precipitation related reflectivity measurements; the effect of overshooting ground clutter targets dwarfs the effect of angular error on meteorologically based reflectivities. During periods characterized by elevation angle stability, the RCA measurement should serve as an excellent proxy for calibration change.

\section{Summary and Conclusions}

This paper presents a method for monitoring the sensitivity of a radar from day to day. It uses a large set of echoes from ground clutter at the lowest beam elevation to provide a stable reference cumulative probability distribution (CDF) of equivalent reflectivity $Z_{c}$ of the clutter echoes. This is done automatically daily with and without rain. The CDF in the presence of rain is due to the sum of the rain reflectivities $\mathrm{Z}_{\mathrm{r}}$ plus Zc. Any change in radar sensitivity displaces the cumulative percentiles by an amount corresponding to that change. The $95^{\text {th }}$ percentile of the CDF of $\left(\mathrm{Zr}_{r}+\mathrm{Z}_{c}\right)$ is found to be a reliable measure of the change in sensitivity.

This method for Relative Calibration Adjustment (RCA) has been used to provide a long term record of system sensitivity for the KPOL radar at Kwajalein, the only 
rainfall ground truth radar in the tropical Pacific for the Tropical Rainfall Measuring Mission (TRMM). It has revealed previously undetected changes in sensitivity due either to intentional or unknown causes, such as system modifications, antenna offsets, alterations of the receiver, or the data processor. It is thus making possible the correction of the radar rainfall measurements and insuring the integrity of $71 / 2$ years of TRMM observations which have become the basis for the near global climatology of the water budget as well as other purposes such as the monitoring of hurricane intensity. The method is applicable to any ground based radar which does not use Doppler filtering of clutter. Readers interested in learning more about the GV program's near-real-time monitoring of KPOL performance may access http://trmm-fc.gsfc.nasa.gov/KWAJ/RCA for further information.

\section{Acknowledgments}

This study was funded by NASA Grants NNG07EJ50C and NNG06HX18C. The authors would like to thank Dr. Ramesh Kakar (NASA Headquarters), Dr. Robert Adler (TRMM Project Scientist) and Mr. Richard Lawrence (Chief, TRMM Satellite Validation Office) for their guidance and support of this effort. We are grateful to Dr. Merrill Skolnik for discussions of ground clutter and to Mr. Bartie Kelley for developing the 
suite of routines in the RSL in IDL library which were the foundation for the programming effort undertaken in this project. We also appreciate the support staff of the TSVO, including David Makofski and Marcella Shupp. 


\section{REFERENCES}

Billingsley, J. B., 1993,: Ground Clutter Measurements for Surface-Sited Radar, MIT Lincoln Laboratories, Lexington, Mass., Tech. Rep. 786, 81 pp.

Billingsley, J. B. and J. F. Larrabee, 1991: Multifrequency Measurements of Radar Ground Clutter at 42 Sites, MIT Lincoln Laboratories, Lexington, Mass., Tech. Rep. 916, Vol. 1, 279 pp.

Fabry, F., 2004: Meteorological value of ground target measurements by radar. J. Atmos. Oceanic Technol., 21, 560-573.

Fabry, F., G. Frush, A. Kilambi, and I. Zawadzki, 1997: On the extraction of near-surface index of refraction using radar measurements of ground targets. J. Atmos. Oceanic Technol., 14, 978-987.

Houze, R. A., Jr., S. Brodzik, C. Schumacher, S. E. Yuter, and C. R. Williams, 2004: Uncertainties in Oceanic Radar Rain Maps at Kwajalein and Implications for Satellite Validation. J. Appl. Meteor., 43, 1114-1132. 
Kozu, T., and Coauthors, 2001: Development of Precipitation Radar Onboard the Tropical Rainfall Measuring Mission (TRMM) Satellite, IEEE Trans. Geosci. Remote Sens., 39, 102-116.

Rinehart, R. E., 1978: On The Use of Ground Return Targets for Radar Reflectivity Calibration Checks. J. Appl. Meteor., 17, 1342-1350.

Skolnik, M., 2001: Introduction to Radar Systems, McGraw-Hill, 772 pp.

Smith, P. L., V. Chandrasekar and E. A. Mueller, 2007: Alignment and Calibration Studies of The KPOL Weather Radar - 2006, 78 pp. [ Available from 3D Research Corporation, Huntsville, Alabama 35806. ]

Wolff, D. B., D. A. Marks, E. Amitai, D. S. Silberstein, B. L. Fisher, A. Tokay, J. Wang, and J. L. Pippitt, 2005: Ground Validation for the Tropical Rainfall Measuring Mission (TRMM). J. Atmos. Oceanic Technol., 22, 365-380.

Yuter, S. E., R. A. Houze Jr., E. A. Smith, T. T. Wilheit, and E. Zipser, 2005: Physical Characterization of Tropical Oceanic Convection Observed in KWAJEX J. Appl. 
Meteor., 44, 385-415. 


\section{LIST OF FIGURES}

Fig. 1. Aerial view of Kwajalein Island. The KPOL radar is located at the southern edge of the island, near the airport runway.

Fig. 2. Map of the clutter field at Kwajalein. Range rings are drawn at $10 \mathrm{~km}$ intervals from the radar site.

Fig. 3. Comparison of two daily PDFs/CDFs from August 2003. The horizontal dotted line represents the $95^{\text {th }}$ percentile of the CDFs. Failure of the CDF (PDF) curves to converge at the upper percentiles (reflectivities) is an indication of calibration instability.

Fig. 4. Comparison of two daily PDFs/CDFs from October 2001. The horizontal dotted line represents the $95^{\text {th }}$ percentile of the CDFs. Convergence of the CDF (PDF) curves at the upper percentiles (reflectivities) is indicative of stable radar calibration.

Fig. 5. Time record of the $95^{\text {th }}$ percentile of daily CDFs of clutter field reflectivity at Kwajalein. 
Fig. 6. Time record of the relative calibration adjustment (RCA) based upon the $95^{\text {th }}$ percentile of the CDFs of clutter field reflectivity displayed in Fig. 5. The RCA is calculated by subtracting the $95^{\text {th }}$ percentile value from the baseline value of 50 .

Fig. 7. Time record showing KPOL calibration offsets from the TRMM-GV RCA method compared with University of Washington (UW) offset.

Fig. 8. Time record of the $95^{\text {th }}$ percentile of clutter field reflectivity for 2000 and 2001 . “a" through " $d$ " mark four separate events described in Table 3 where engineering issues impacted the time record. The solid horizontal line represents the baseline reflectivity used in the calculation of the RCA.

Fig. 9. Comparison of two daily PDFs/CDFs from May 2004. The horizontal dotted line represents the $95^{\text {th }}$ percentile of the CDFs. Failure of the CDF (PDF) curves to converge at the upper percentiles (reflectivities) is an indication of calibration instability.

Fig. 10. Raw reflectivity images for 08 UTC on 7 May 2004 (a) and 8 May 2004 (b). Identical reflectivity color tables are used for both images. Range rings are plotted at 50 km intervals. 
Fig. 11. Comparison of three daily PDFs illustrating effects of radar calibration offset.

Fig. 12. Time record of the relative calibration adjustment (RCA) illustrating impact of calibration offset.

Fig. 13. Time record of the relative calibration adjustment (RCA) displaying radar elevation angle modification during periods marked "a" and " $b$ ". 


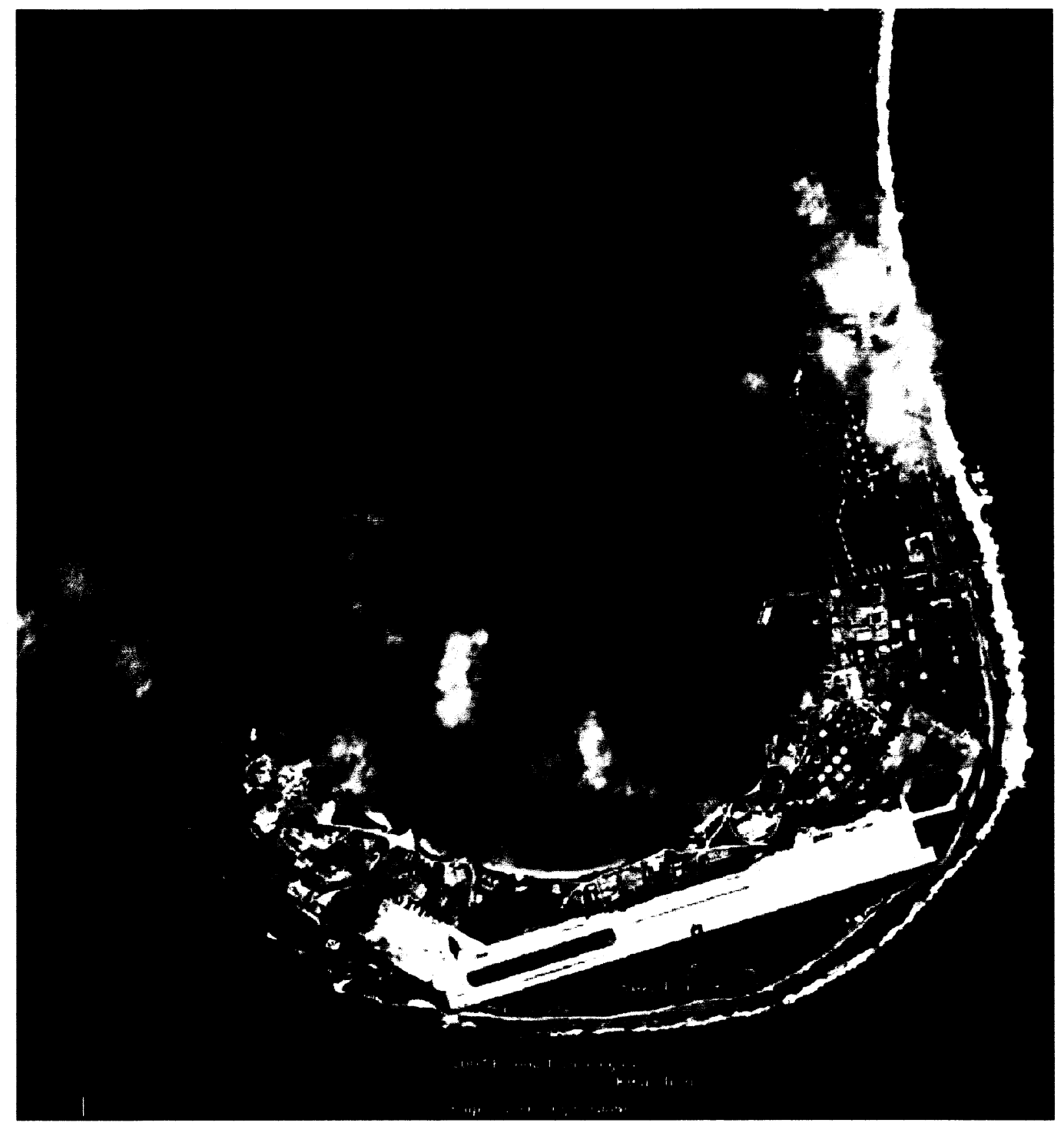

Fig. 1. Aerial view of Kwajalein Island. The KPOL radar is located at the southern edge of the island, near the airport runway. 


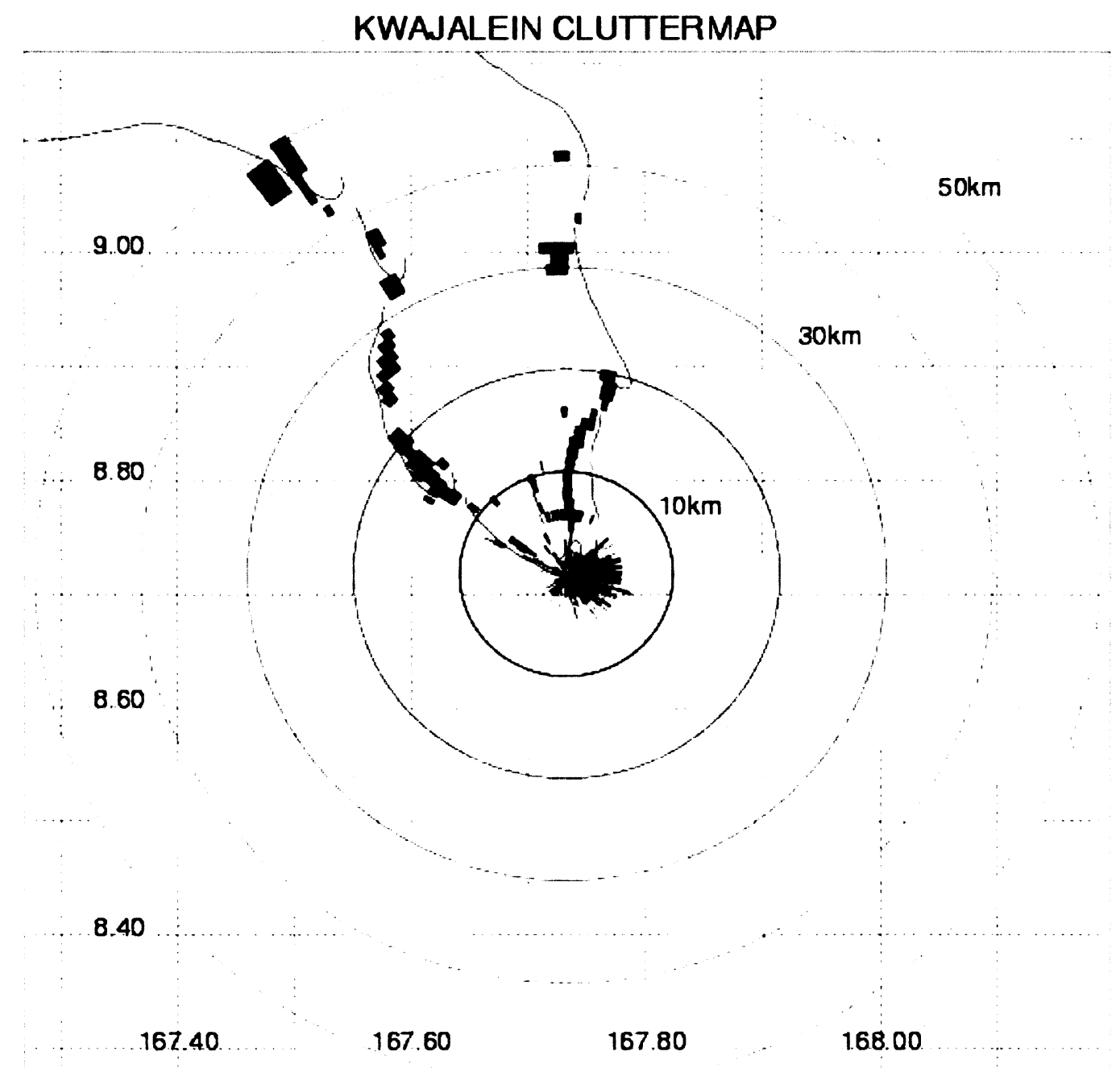

Fig. 2. Map of the clutter field at Kwajalein. Range rings are drawn at $10 \mathrm{~km}$ intervals from the radar site. 


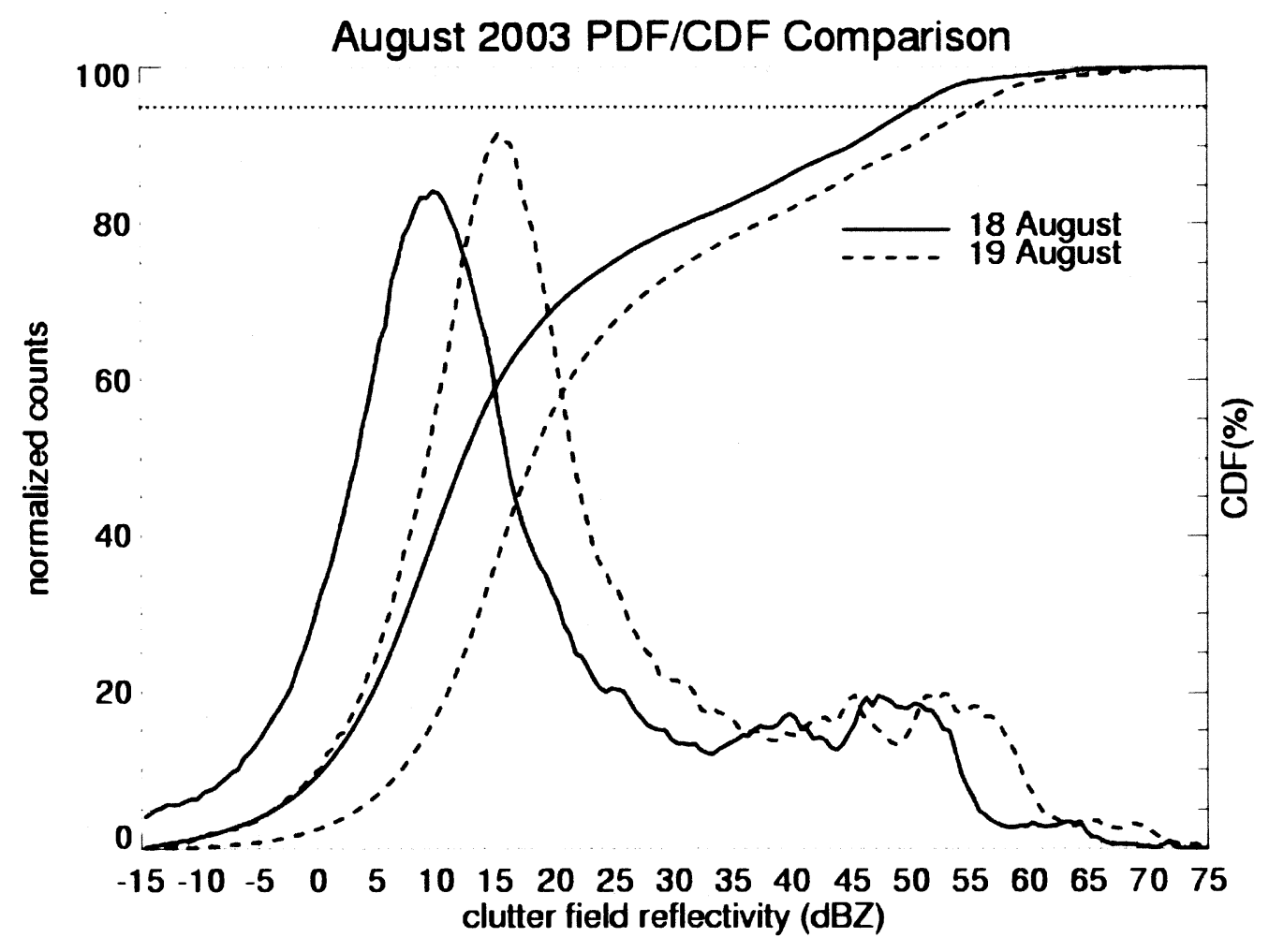

Fig. 3. Comparison of two daily PDFs/CDFs from August 2003. The horizontal dotted line represents the $95^{\text {th }}$ percentile of the CDFs. Failure of the CDF (PDF) curves to converge at the upper percentiles (reflectivities) is an indication of calibration instability. 


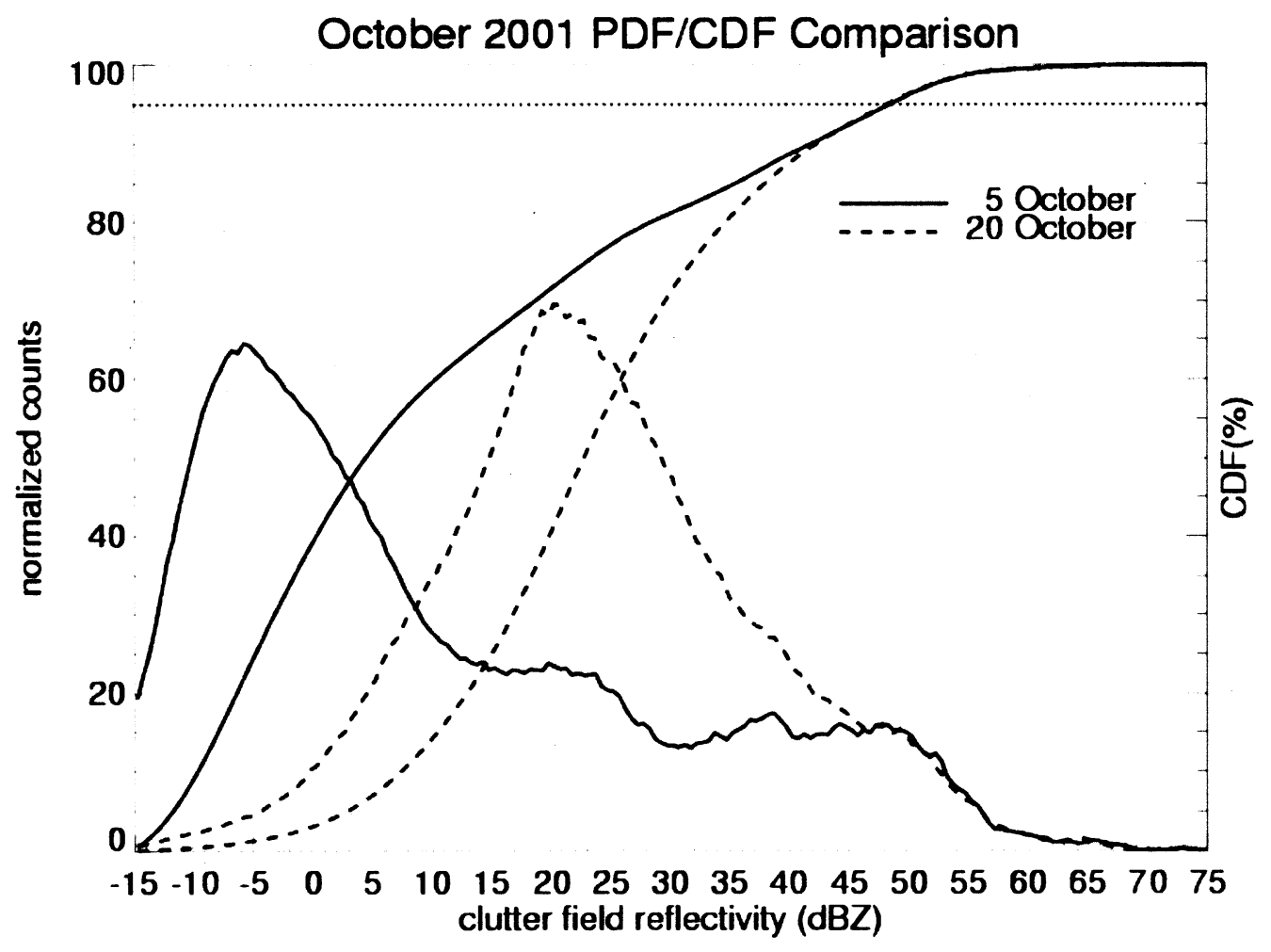

Fig. 4. Comparison of two daily PDFs/CDFs from October 2001. The horizontal dotted line represents the $95^{\text {th }}$ percentile of the CDFs. Convergence of the CDF (PDF) curves at the upper percentiles (reflectivities) is indicative of stable radar calibration. 


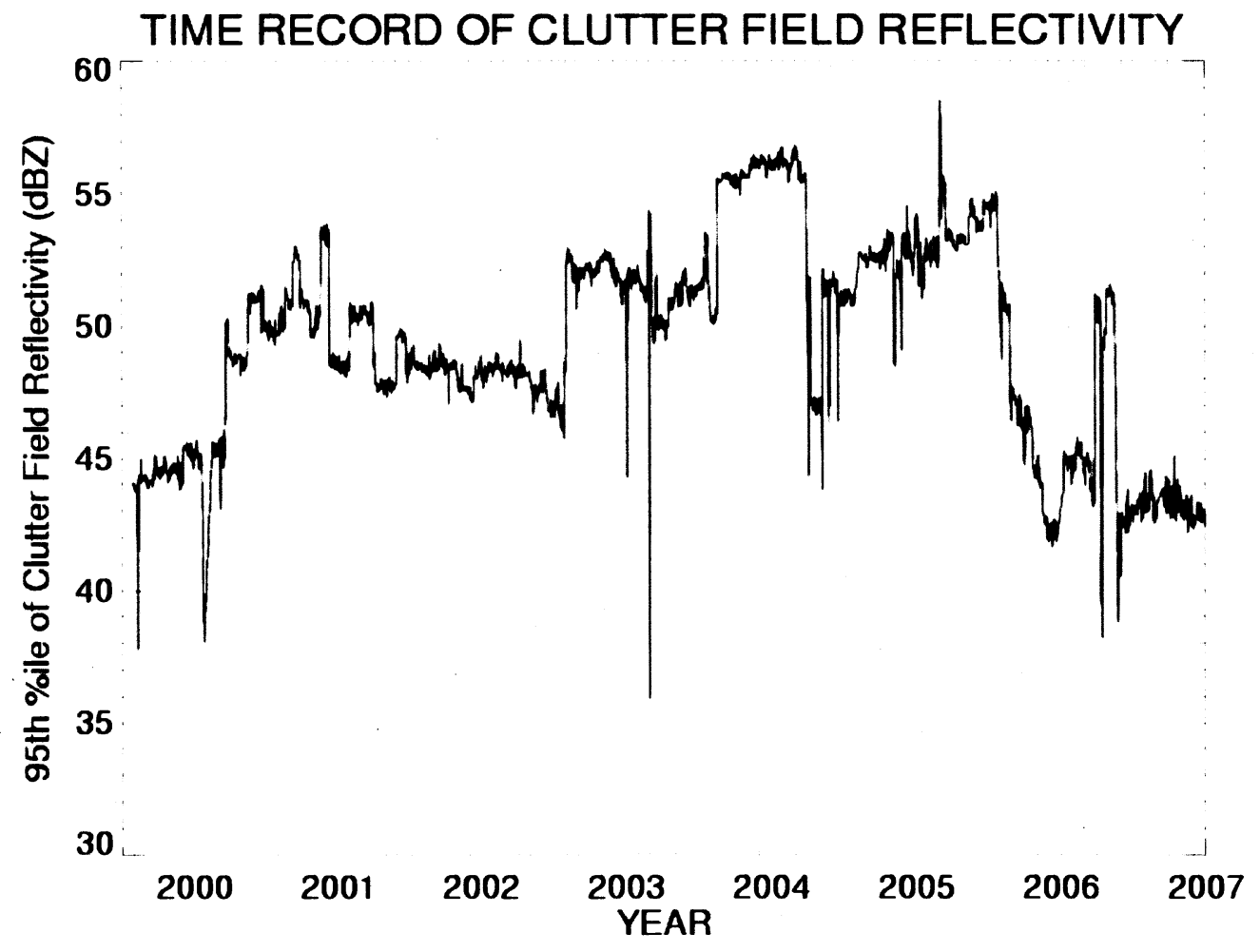

Fig. 5. Time record of the $95^{\text {th }}$ percentile of daily CDFs of clutter field reflectivity at Kwajalein. 


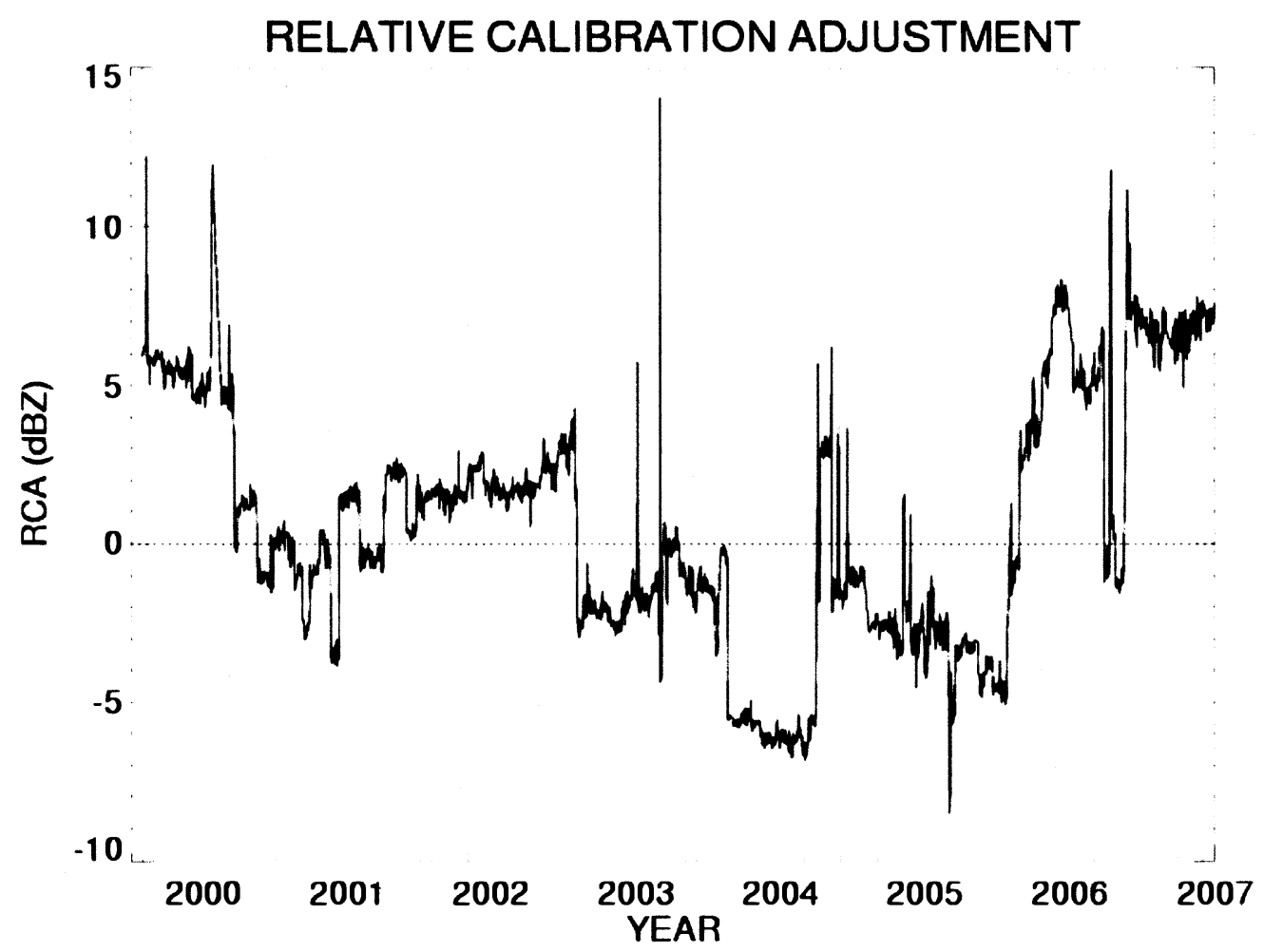

Fig. 6. Time record of the relative calibration adjustment (RCA) based upon the $95^{\text {th }}$ percentile of the CDFs of clutter field reflectivity displayed in Fig. 5. The RCA is calculated by subtracting the $95^{\text {th }}$ percentile value from the baseline value of 50 . 
15

UW Calibration Offset

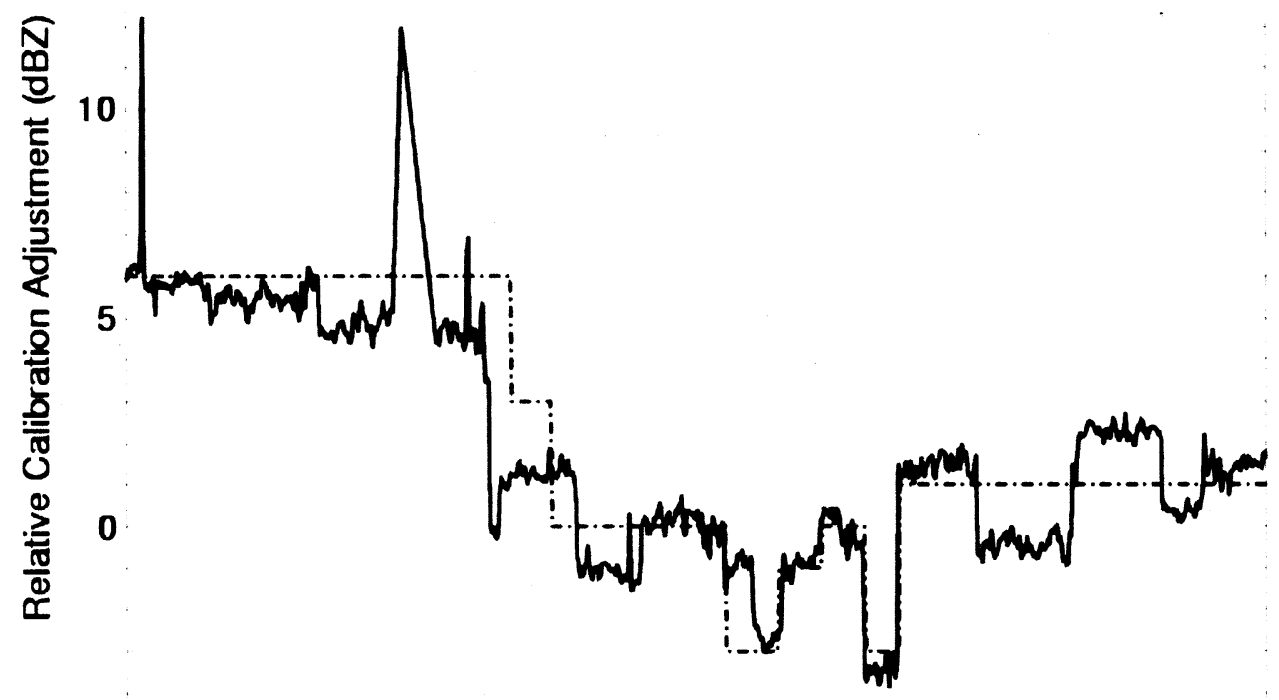

$-5$

AUG '99 JAN '00

JAN '01

AUG '01

Fig. 7. Time record showing KPOL calibration offsets from the TRMM-GV RCA method compared with University of Washington (UW) offset. 


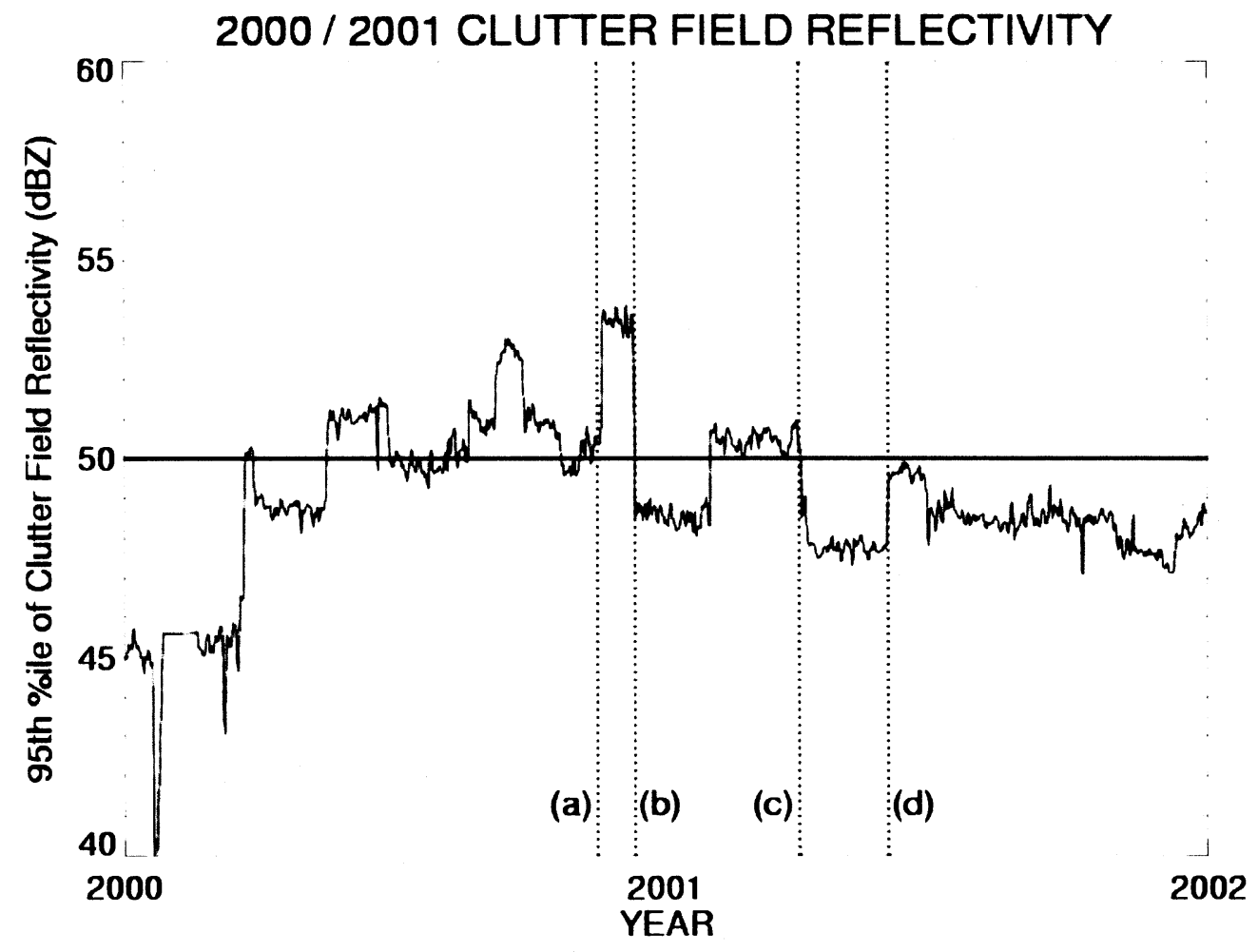

Fig. 8. Time record of the $9^{\text {th }}$ percentile of clutter field reflectivity for 2000 and 2001. " $a$ " through " $d$ " mark four separate events described in Table 3 where engineering issues impacted the time record. The solid horizontal line represents the baseline reflectivity used in the calculation of the RCA. 


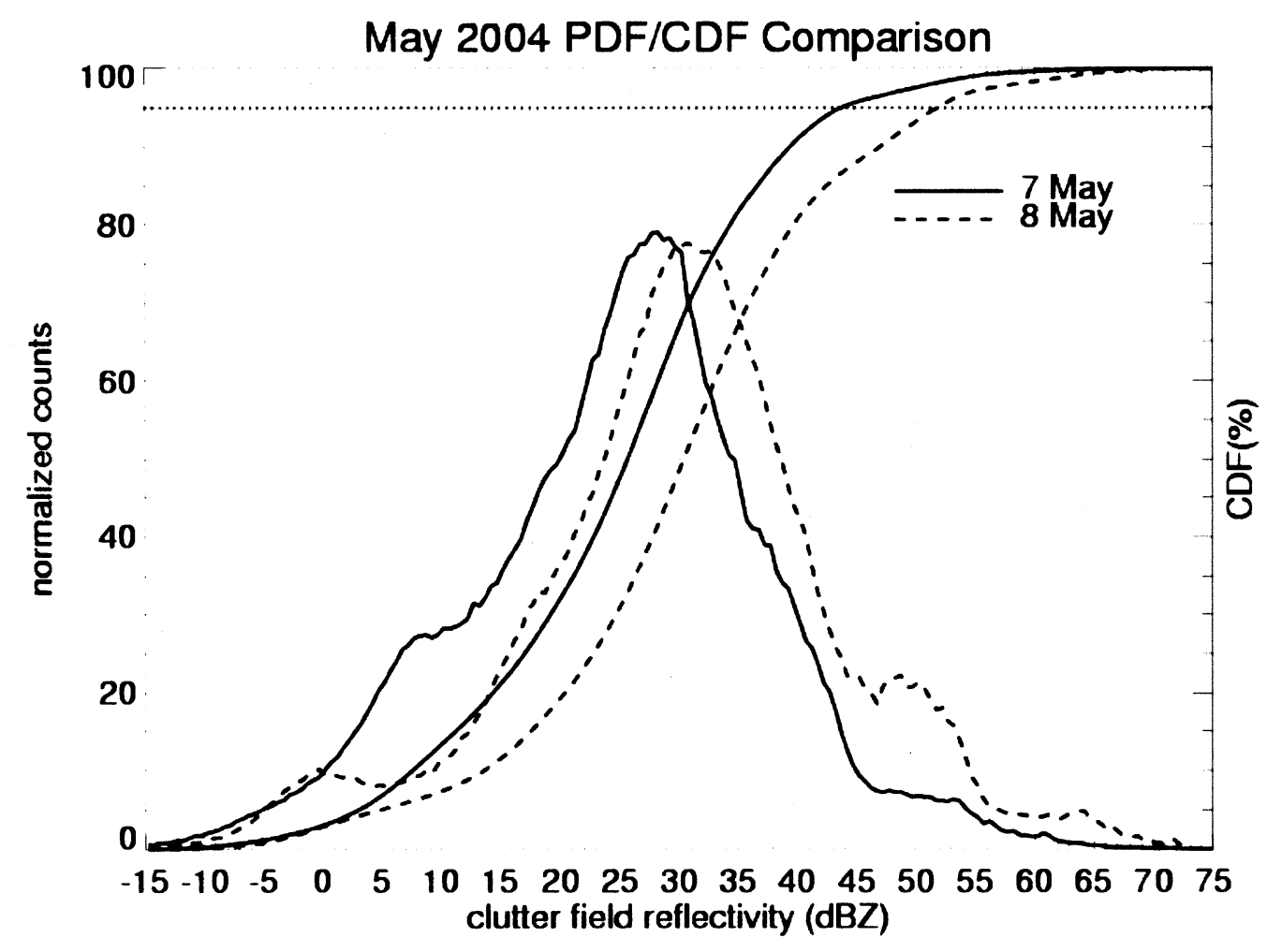

Fig. 9. Comparison of two daily PDFs/CDFs from May 2004. The horizontal dotted line represents the $95^{\text {th }}$ percentile of the CDFs. Failure of the CDF (PDF) curves to converge at the upper percentiles (reflectivities) is an indication of calibration instability. 


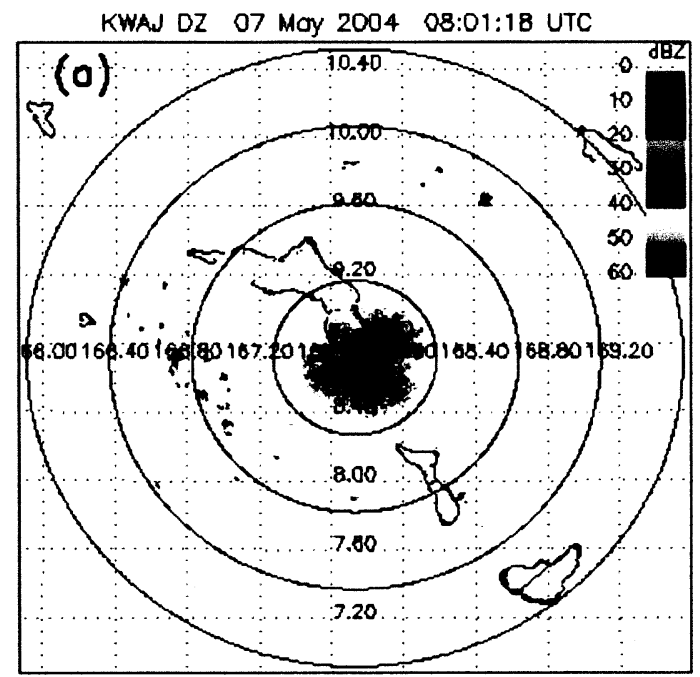

KWAJ DZ O8 MOY 2004 08:01:23 UTC

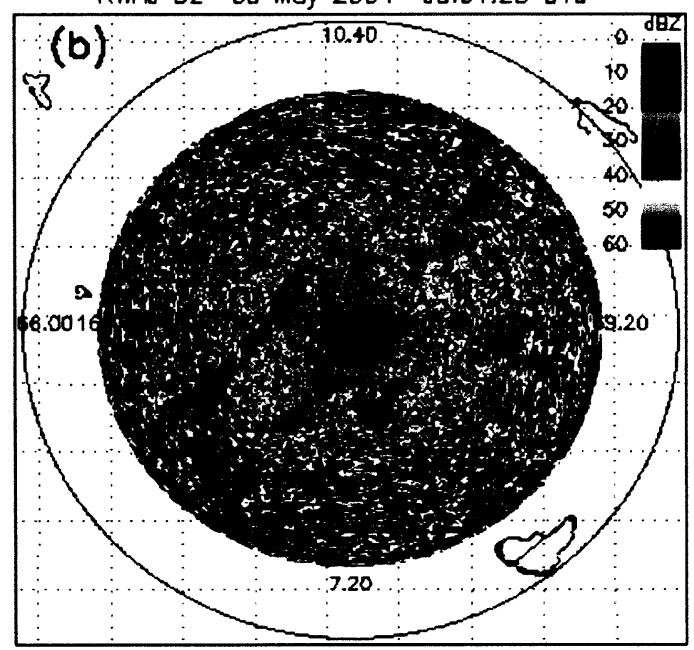

Fig. 10. Raw reflectivity images for 08 UTC on 7 May 2004 (a) and 8 May 2004 (b). Identical reflectivity color tables are used for both images. Range rings are plotted at 50 km intervals. 


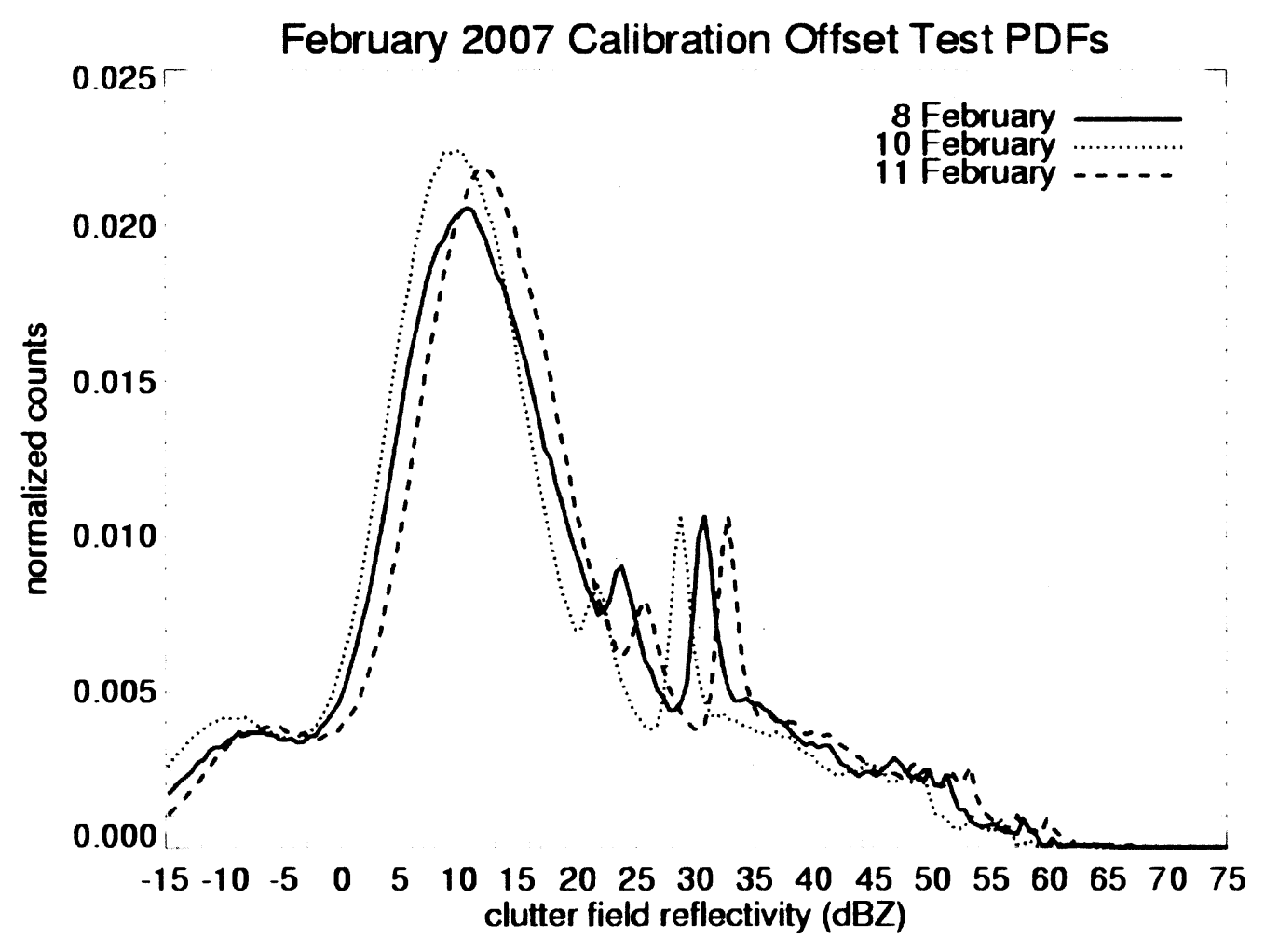

Fig. 11. Comparison of three daily PDFs illustrating effects of radar calibration offset. 


$$
12\ulcorner
$$

February 2007 RCA Time Record

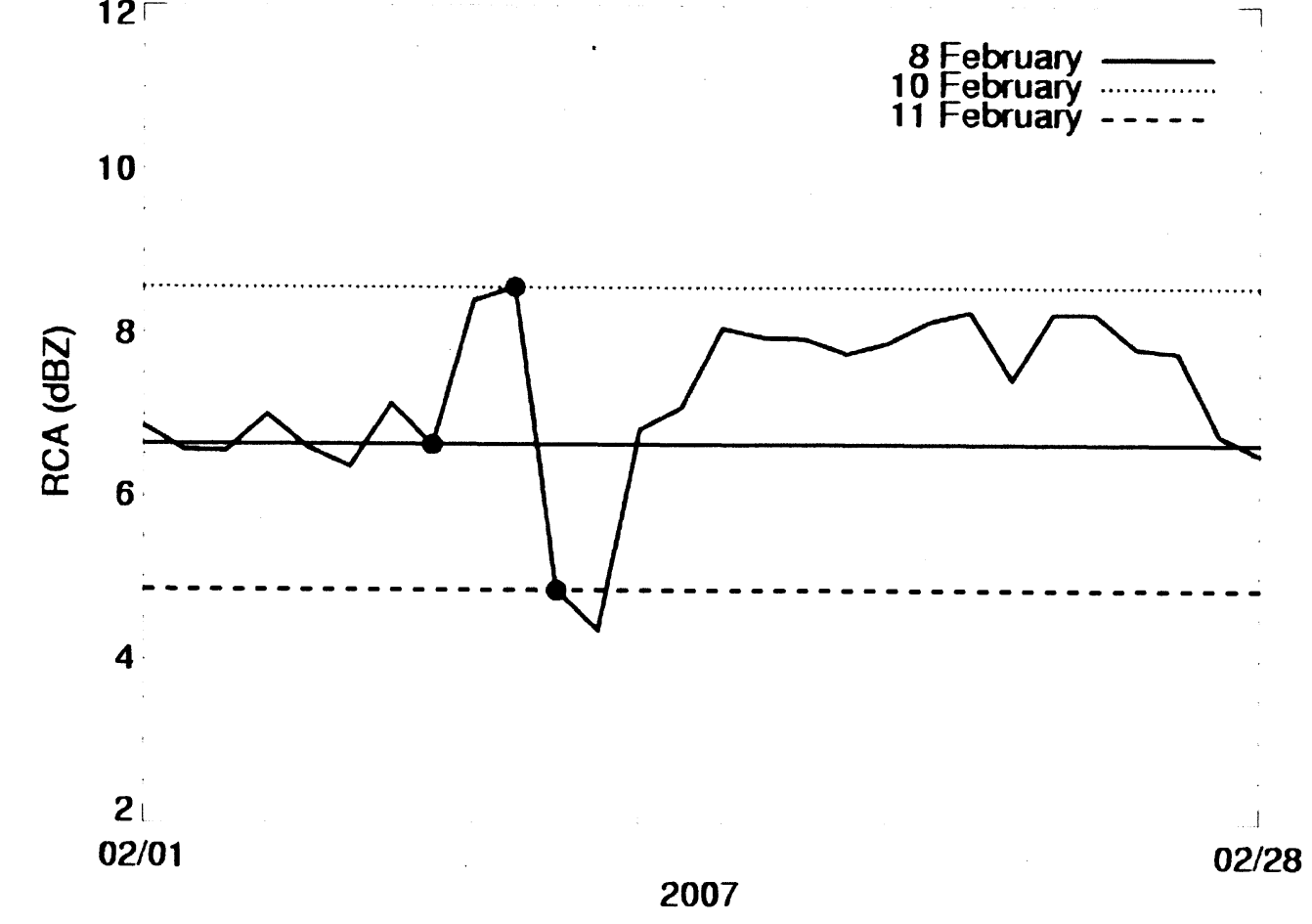

Fig. 12. Time record of the relative calibration adjustment (RCA) illustrating impact of calibration offset. 


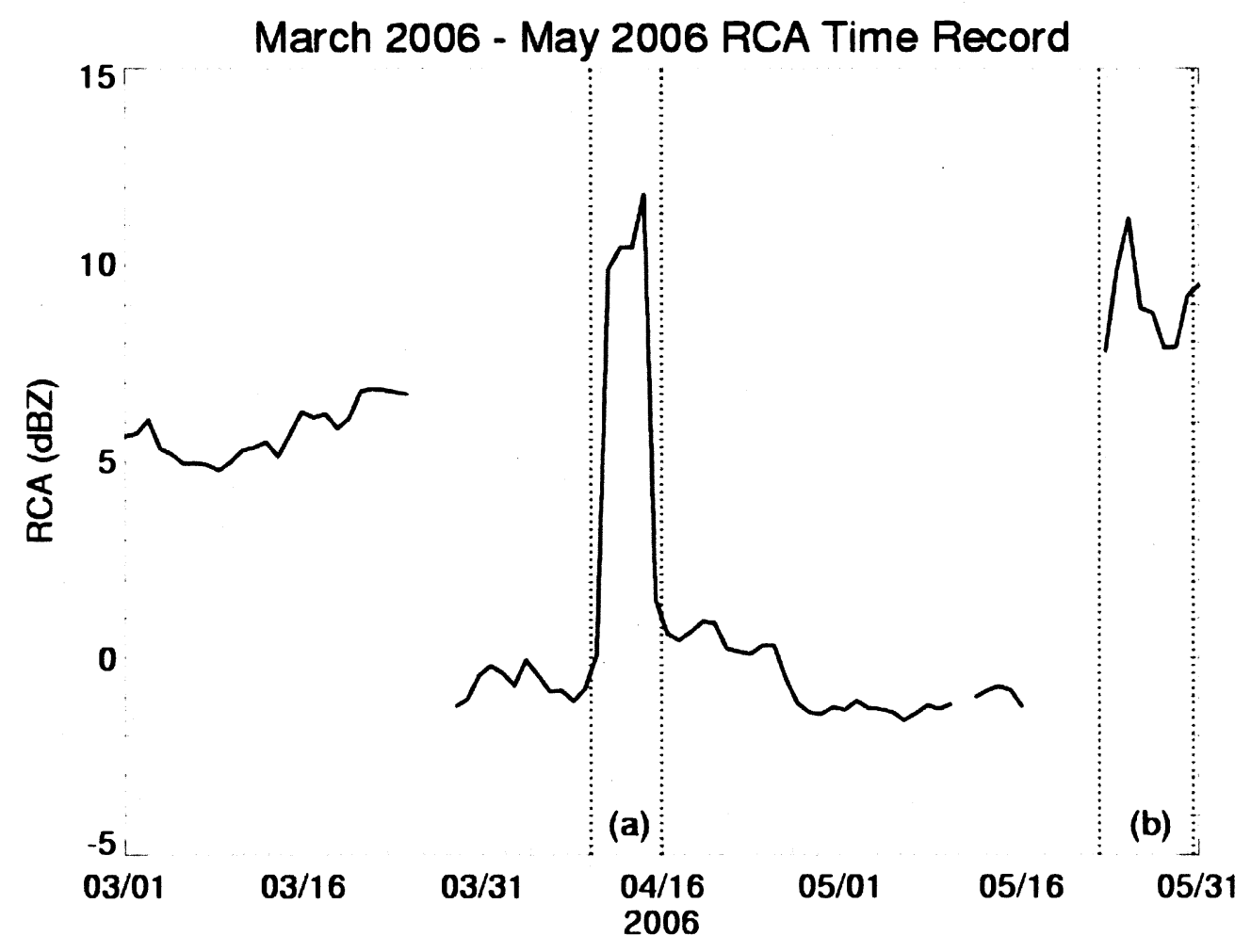

Fig. 13. Time record of the relative calibration adjustment (RCA) displaying radar elevation angle modification during periods marked "a" and " $b$ ". 
Table 1. Characteristics of the Kwajalein (KPOL) radar located on Kwajalein Island at the southern tip of Kwajalein Atoll in the Republic of the Marshall Islands.

\begin{tabular}{ll}
\hline & Kwajalein KPOL Radar Characteristics \\
\hline & \\
Frequency Range: & $2800 \mathrm{MHz}$ \\
Wavelength: & $10.71 \mathrm{~cm}$ \\
Peak Power: & $700 \mathrm{~kW} \mathrm{@} 58.5 \mathrm{~dB}$ \\
Normal Power: & $500 \mathrm{~kW}$ \\
Pulse width: & $1.67 \times 10^{-6} \mathrm{~s}$ \\
PRF Intensity: & $264-1536 \mathrm{~Hz}$ \\
Radar Range (maximum) & $450 \mathrm{~km}(243 \mathrm{~nm})$ \\
Velocity: & $150 \mathrm{~km}(81 \mathrm{~nm})$ \\
Antenna Gain: & $43.8 \mathrm{~dB}$ \\
Antenna Diameter: & $8.2 \mathrm{~m}(27 \mathrm{ft})$ \\
Antenna Beamwidth: & $1.1^{\circ}$ \\
Height to Center of Antenna: & $20.7 \mathrm{~m}(68 \mathrm{ft})$ \\
Input Power: & $110 / 220 \mathrm{~V}$ single phase @ 7.5-10.0 kW
\end{tabular}


Table 2. Distribution of Clutter Points as a Function of Range From KPOL

\begin{tabular}{cc}
\hline Distance From Radar $(\mathbf{k m})$ & Number of Clutter Points \\
\hline 1 & 296 \\
2 & 307 \\
3 & 202 \\
4 & 132 \\
5 & 81 \\
6 & 48 \\
7 & 42 \\
8 & 15 \\
9 & 9 \\
10 & 8 \\
$>10$ & 183
\end{tabular}


Table 3. Description of Engineering Events Depicted in Fig. 8

\begin{tabular}{ccll}
\hline Event & Date & \multicolumn{1}{c}{ Radar Log Account } & Magnitude of Change (dB) \\
\hline a & $11 / 19 / 00$ & Pulse Forming Network Replaced & $\sim 3$ \\
b & $12 / 12 / 00$ & Pulse Forming Network Replaced & $\sim 4.5$ \\
c & $04 / 02 / 01$ & Antenna Gain Decrease & $\sim 3$ \\
d & $05 / 31 / 01$ & Antenna Gain Increase & $\sim 2$
\end{tabular}


Table 4. Day-To-Day $\triangle \mathrm{RCA}(\mathrm{dB})$ During July 2007 Illustrating Range Effect

\begin{tabular}{cccc}
\hline Date & $\Delta \mathrm{RCA}(10 \mathrm{~km}$ limit $)$ & $\Delta \mathrm{RCA}(5 \mathrm{~km}$ limit $)$ & $\Delta \mathrm{RCA}(1 \mathrm{~km}$ limit $)$ \\
\hline $07 / 11$ & -0.41 & -0.46 & -0.12 \\
$07 / 12$ & 0.03 & 0.02 & 0.01 \\
$07 / 13$ & 0.23 & 0.22 & 0.06 \\
$07 / 14$ & 0.31 & 0.26 & 0.19 \\
$07 / 15$ & 0.10 & 0.12 & -0.05 \\
$07 / 16$ & -0.18 & -0.19 & -0.09 \\
$07 / 17$ & -0.28 & -0.28 & 0.08 \\
$07 / 18$ & 0.25 & 0.33 & -0.04 \\
$07 / 19$ & 0.15 & 0.13 & -0.04 \\
$07 / 20$ & -0.19 & -0.20 & 0.03
\end{tabular}

